\title{
El rol del Estado en el cercamiento de las semillas en Argentina
}

\section{The State's role in enclosing seeds in Argentina}

Tamara Perelmuter

Doctora en Ciencias Sociales. Becaria Postdoctoral del Consejo Nacional de Investigaciones Científicas y Técnicas CONICET. Instituto de Estudios sobre América Latina y el Caribe IEALC. Facultad de Ciencias Sociales. Universidad de Buenos Aires. Marcelo T. de Alvear 2230, (1122) Ciudad Autónoma de Buenos Aires, Buenos Aires, Argentina, tamiperelmuter@gmail.com, ORCID https://orcid.org/0000-0003-4331-1872

Recibido: 24 de abril 2020 || Aprobado: 13 de julio 2020

Resumen

El cercamiento de las semillas en Argentina aunque fue profundizado en las últimas décadas, viene de larga data. Articula dos procesos: las transformaciones en el modelo agrario que acompañan los cambios técnicos y los cambios en el marco jurídico de la propiedad intelectual. En este artículo analizamos cinco momentos del cercamiento de las semillas en el caso argentino: 1. Sanción de la Ley de Granos y Elevadores (1935); 2. Revolución Verde y sanción de la Ley de Semillas (1973); 3. Neoliberalismo de la década del 1990 con la aparición de la agrobiotecnología (1990-2002); 4. Kirchnerismo y comienzo de la discusión por la modificación de la Ley de Semillas (2003-2015); y 5. Cambio de etapa política que significó la llegada de Cambiemos al gobierno (2016-2019). En cada periodo visualizamos el rol del Estado en relación al mejoramiento, la conservación y la apropiación de las semillas con el objetivo de identificar los procesos de estatalización/des-estatalización y de mercantilización/des-mercantilización.

Palabras clave: Cercamiento; Semillas; Estado; Argentina

Abstract

The enclosure of seeds in Argentina, although it has been deepened in recent decades, has been around for a long time. It articulates two processes: the transformations in the agrarian model that accompany the technical changes; and changes in the legal framework of intellectual property. In this article we analyze five moments of the enclosure of seeds in the Argentine case: 1 . Sanction of the Grain and Elevator Law (1935); 2. Green Revolution and sanction of the Seed Law (1973); 3. Neoliberalism of the 1990s with the appearance of agrobiotechnology (1990 - 2002); 4. Kirchnerism and beginning of the discussion for the modification of the Seed Law (2003-2015); 5. Change of political stage that meant the arrival of Cambiemos to the government (2016-2019). In each period we visualize the role of the State in relation to the improvement, conservation and appropriation of seeds with the aim of identifying the processes of nationalization / de-nationalization and commodification / de-commodification.

Key words: Enclosure; Seeds; State; Argentina

Cita sugerida: Perelmuter, T. (2020). El rol del Estado en el cercamiento de las semillas en Argentina. Estudios Socioterritoriales. Revista de Geografía, (28), 060. DOI: https://doi.org/10.37838/unicen/est.28-060 
INTRODUCCIÓN

El cercamiento de los commons, proceso que Marx (2000) describió como de acumulación originaria, consistió en el despojo de los comuneros de sus tierras y en su privatización. Diversos autores y autoras (Luxemburgo, 2007; Bonefeld, 2001; De Angelis, 2001; Dalla Costa, 2004) han puntualizado que la acumulación originaria no es solo la etapa que dio origen al capitalismo, sino un proceso continuo y permanente de separación de los productores de sus medios de producción y de subsistencia. Esto ha sido caracterizado por David Harvey (2004) como acumulación por desposesión.

Luego de la crisis y reconfiguración del capitalismo durante la década de 1970 estamos asistiendo a una profundización de los procesos de cercamiento que supone que aquello que aún era común o no estaba del todo incluída a las lógicas del mercado, se está rápidamente mercantilizando conforme a nuevos regímenes de propiedad. Esta ampliación no es más que la subsunción de todos los aspectos sociales de la vida humana a los requerimientos de la acumulación capitalista. Esto está sostenido sobre la base de un salto científico-tecnológico que está ampliando a niveles inimaginables la escala de apropiación privada del trabajo colectivo y la naturaleza (Gilly y Roux, 2009).

La semilla es un organismo vivo que puede reproducirse y es por esto que ha sido difícil transformarla en una mercancía. Sin embargo, el capital buscó siempre diversas estrategias para sortear esta dificultad (Kloppenburg, 2005). Por lo tanto, no quedaron fuera de los cercamientos que se dan a partir de dos tipos de mecanismos articulados entre sí y que facilitan su apropiación.

Por un lado, el cercamiento agrario, que remite las transformaciones en los modelos que acompañan los cambios técnicos de las semillas: 1. La reestructuración agraria iniciada con la denominada Revolución Verde aplicada a los países del Sur a partir de mediados del siglo XX significó la expresión en el agro de la necesidad de la reconfiguración global del capital (Cleaver, 1972). Se masificaron las semillas híbridas para la siembra, que suponen un proceso de cruzamiento entre dos individuos de diferentes especies, rompiendo la identidad semillas-grano. Por lo tanto, significaron la separación del agricultor de su capacidad de replantar y el comienzo de la dependencia de las empresas que proveen los insumos (Gárgano, 2013); 2. La reconfiguración productiva llegó a su etapa de consolidación con los agronegocios, en tanto expresión del neoliberalismo en el agro. En este modelo, el pilar tecnológico es central. La expansión de biotecnología agraria aplicada al agro que dio lugar a las semillas transgénicas condujo a grandes cambios en las estrategias de privatización del conocimiento habilitando nuevos mecanismos de acumulación de capital (López Monja, Poth y Perelmuter, 2010). Por lo tanto, las semillas se volvieron un punto de interés estratégico en el desarrollo de la agricultura global (Kloppenburg, 2005).

Por otro lado, el cercamiento jurídico, que remite a los cambios en las formas de apropiación de las mismas, en el que el rol de los Derechos de Propiedad Intelectual (DPI) son fundamentales (Boyle, 2003). Los DPI sobre las semillas contempla básicamente

1 La biotecnología moderna es aquella tecnología que utiliza técnicas de ingeniería genética para la manipulación de seres vivos. Esta se ha desarrollado a partir del descubrimiento y la lectura de las cadenas de ADN y la decodificación del genoma. A partir de técnicas recombinantes, lo que en un primer momento se basaba en la observación y descubrimientos de las fórmulas de ADN en seres vivos, se transformó en la posibilidad de escindir cromosomas y reinsertarlos en pares diferentes a los fines de modificar ciertas características del individuo estudiado. 
dos formas: los derechos de obtentor (DOV), otorgados a quienes producen variedades mejoradas de semillas agrícolas para explotarla en exclusividad, pero no alcanzan al producto obtenido y son válidos para todo tipo de semillas; y las patentes de invención, derecho monopólico exclusivo otorgado por un Estado a quien realiza una invención, es decir, un producto o procedimiento que aporta una nueva manera de hacer algo. Con la aparición de la biotecnología, las patentes fueron extensivas también a las semillas, que previamente no eran consideradas una invención, y por lo tanto, no podían ser patentadas. Se trata de una protección más amplia que el DOV, ya que alcanza al producto y sucesivas generaciones del vegetal, extendiéndose la protección de la planta entera en las semillas patentadas. Y se aplican solo a semillas transgénicas, ya que lo que se patenta es el evento transgénico, es decir, la manipulación genética (Perelmuter, 2011).

Comprender el cercamiento como una lógica atravesada por relaciones sociales inmersas en una determinada dinámica de acumulación capitalista, implica también poder revisar las formas de dominación política que se (re)configuran en este proceso. Por este motivo, el análisis del Estado se vuelve nodal en nuestro trabajo.

La historia de Argentina está entrelazada con la agricultura. Desde la imagen granero del mundo en la víspera del siglo XX (Leguizamón, 2020) hasta el lugar actual del país en la cadena mundial de la soja (Motta 2016), la agricultura ha jugado un papel central. En la actualidad, desempeñando un papel clave en la expansión de los cultivos transgénicos en el régimen alimentario mundial contemporáneo, se presenta como un sitio estratégico para investigar el cercamiento de las semillas, las disputas generadas, y el papel del Estado.

El cercamiento de las semillas en Argentina, aunque profundizado en las últimas décadas, viene de larga data. En este artículo analizamos cinco momentos del cercamiento de las semillas en el caso argentino con el objetivo de identificar en cada uno el rol del Estado: 1. Sanción de la Ley de Granos y Elevadores (1935); 2. Revolución Verde y sanción de la Ley de Semillas (1973); 3. Neoliberalismo de los años noventa con la aparición de la agrobiotecnología (1990-2002); 4. Kirchnerismo y comienzo de la discusión por la modificación de la Ley de Semillas (2003-2015) y; 5. Cambio de etapa política que significó la llegada de Cambiemos al gobierno (2016-2019). En cada periodo visualizamos el rol del Estado en relación al mejoramiento, la conservación y la apropiación de las semillas con el objetivo de identificar los procesos de estatalización/des-estatalización y de mercantilización/des-mercantilización (Bonnet, 2011).

Los análisis de esta contribución se basan en la revisión de la legislación nacional e internacional de los DPI; y en el análisis bibliográfico sobre el tema de investigación. Un dato importante a destacar es que la producción académica en Argentina vinculada con las DPI en semillas es visiblemente menor a la existente en algunos países de América Latina. Esto se modificó, en parte, en los últimos cinco años cuando comenzó a discutirse con mayor intensidad la posibilidad de modificar la Ley de Semillas.

\section{Algunos debates Conceptuales en tORno al Estado}

Entendemos al Estado como una relación social (Holloway y Picciotto, 1980; Osorio, 2014). Es la relación básica de dominación que existe en una sociedad, la que separa a los dominantes de los dominados en una estructura social; es la que regula el conflicto entre explotadores y explotados (O'Donnell, 1984; Thwaites Rey, 2001; Ouviña, 2002). Es el resultado y la condición de continuidad de la separación entre lo político (lugar de 
la dominación) y lo económico (lugar de la explotación) del Estado capitalista (Holloway, 1994), proceso que se origina en la separación histórica del productor de sus medios de producción, dando origen a las relaciones capitalistas (Hirsch, 1978; Marx, 2000). Por un lado, el Estado es la forma de coerción extraeconómica que asegura al capitalista el control sobre las mercancías (particularmente, la fuerza de trabajo). Pero también, es el ámbito que garantiza la libertad e igualdad propias del proceso de separación de los productores de los medios de producción (Holloway, 1994)2. De esta manera, el Estado es el espacio prioritario de condensación de las relaciones de fuerza sociales que se plasman materialmente dentro de un territorio acotado, forma dinámica que se va reconstituyendo cotidianamente a partir de las luchas sociales. Siguiendo a Zorzoli:

El Estado como modo de existencia de las relaciones de dominación política, y el capital como modo de existencia de las relaciones de explotación no son hechos constituidos de una vez sino más bien reproducidos cotidianamente, o sea, son procesos cuya reproducción está asociada a la dinámica de las contradicciones y crisis que caracterizan a las relaciones de producción capitalistas. (2018, p. 7)

En las últimas décadas el debate del Estado estuvo atravesado por el proceso de globalización (Beck, 1998) y el problema central fue la relación entre el mercado mundial, por un lado; y el Estado nacional, por el otro (Pascual y Ghiotto, 2010). Y más allá de las diversas interpretaciones realizadas acerca de las causas de la globalización ${ }^{3}$, se tendió a identificar al mercado y al Estado como dos formas constitutivas separadas una de otra, relacionándose entre ellas solo de manera externa.

Pero desde nuestro punto de vista, y siguiendo a Bonnet (2011), tanto el Estado como el mercado capitalista son formas conceptual e históricamente diferenciadas de una misma relación social: el antagonismo entre el capital y el trabajo. Pero de esto, no puede concluirse que ambas nociones guarden entre sí, necesariamente una relación de mutua oposición. Por lo tanto:

(...) tampoco puede concluirse que los procesos de ampliación / restricción de las relaciones estatales (vamos a denominarlos como procesos de estatalización y des-estatalización) resultarán inversamente proporcionales a los procesos de ampliación / restricción de las relaciones mercantiles (de mercantilización y des-mercantilización) (Bonnet, 2011, p. 19) (cursivas en el original)

No se trata entonces de una suerte de juego de "suma cero" (Bonnet, 2011, p. 17), donde necesariamente más Estado implica menos mercado, y viceversa. Por el contrario, la reproducción de las relaciones sociales capitalistas será de reproducción conjunta en tanto relaciones de dominación y explotación, y su devenir dependerá del conjunto del desarrollo de las luchas sociales en cada momento histórico concreto.

El cercamiento de las semillas en Argentina, aunque profundizado en las últimas décadas, viene de larga data. En este artículo nos centraremos en analizar cinco momentos históricos significativos en ese proceso con el objetivo de identificar en cada uno de ellos, los procesos de estatalización/des-estatalización y de mercantilización/ des-mercantilización.

2 Libertad que el productor adquiere cuando es separado de sus medios de producción a los que ya no se encuentra atado, pudiendo vender su fuerza de trabajo; y libertad del ya devenido en trabajador de vender esa fuerza de trabajo a cualquier capitalista que desee.

3 Para Pascual y Ghiotto (2010), las explicaciones de la globalización partieron desde dos posiciones opuestas. Por un lado, quienes lo explican desde iniciativas de los Estados centrales; y por el otro, quienes ponen el énfasis en los actores económicos, es decir, el mercado. 


\section{El ordenamiento del mercado de semillas: La Ley de Granos y Elevadores (1935)}

Argentina se insertó tempranamente al capitalismo mundial en base a sus tierras fértiles productoras de granos, cereales y ganadería por lo que su agricultura, sobre todo en la región pampeana, tuvo desde sus orígenes fuertes rasgos capitalistas (Flichman, 1977). Sin embargo, la historia agrícola de este país es más compleja, contando con importantes áreas de selección y domesticación de variedades de plantas americanas de valor económico y cultural. Al momento de la conquista española al actual territorio argentino, las sociedades cuyos modos de existencia y subsistencia estaban basados en la agricultura o incluían aportes de la recolección y producción de alimentos, se situaban sobre todo en la parte norte y en las zonas cordilleranas de las regiones central y nor-patagónica (Pochettino, Lema, Hilgert y Ladio, 2017) ${ }^{4}$.

Sin embargo, según el relato presentado por el discurso oficial, las primeras semillas que se utilizaron en el país provenían de importaciones hechas por los mismos agricultores inmigrantes, firmas privadas e instituciones oficiales sin mayor previsión técnica (Gutiérrez y Penna, 2004; Harries y Ripoll, 1998). Esto dio lugar a la existencia de una gran variedad de semillas, integrada por poblaciones de diverso grado de heterogeneidad que se difundieron en distintas regiones sin ningún tipo o escasa intervención por parte de los gobiernos.

Hacia fines del siglo XIX se llevaron a cabo las primeras iniciativas del sector público para promover las actividades de fitomejoramiento que se fueron plasmando tanto en la promulgación de leyes como en la creación de instituciones científico-técnicas que garantizaran el incremento de la producción agrícola ${ }^{5}$. En 1912 fue contratado el genetista inglés Guillermo Blackhouse y con él se formaron los primeros fitomejoradores del país, entre ellos, José Buck (inmigrante alemán) y varios jóvenes argentinos que se sumaron a las estaciones experimentales del Ministerio de Agricultura (Harries y Ripoll, 1998). Sin embargo, para ese entonces no existía ningún marco legal que regulara estas actividades, normara el comercio ni fijara las pautas para la difusión o no, de cultivares de acuerdo a su adaptación a las condiciones ecológicas o al comercio de granos en el país.

De esta manera, se fue creando una corriente de opinión favorable a la necesidad de crear un marco legal que lograra la tipificación de nuestros granos (Harries y Ripoll, 1998). Promulgada en 1935, la Ley de Granos y Elevadores $N^{\circ} 12.253$, y dentro de ella el capítulo de Fomento de la Genética (Art. 20 a 27), fue el acontecimiento bisagra en el proceso de cercamiento de las semillas. Se trató de la primera intervención estatal desde un punto de vista estrictamente normativo. Se proponía incentivar la adopción de semillas mejoradas y ordenar el mercado mediante un sistema de fiscalización de la producción y de la comercialización con una activa participación del sector público en esta etapa (Gutiérrez, 1984).

Asimismo, también durante la década de 1930 se formaron las primeras colecciones de germoplasma de trigo, maíz y maní, con el establecimiento de programas de mejoramiento por parte de los colonos europeos y los primeros fitomejoradores

4 En el noroeste, por ejemplo, la agricultura local albergó especies que, en su mayoría, no forman parte de los actuales cultivos industriales, convirtiéndose en un área de importancia en la domesticación de variedades de cultivos andinos importantes como maíces, ajíes, porotos, zapallos.

5 En 1867 se fundó el Instituto Agrícola en Santa Catalina, provincia de Buenos Aires con la presencia de científicos europeos. En 1871 se creó el Departamento Nacional de Agricultura por parte del gobierno de Domingo Faustino Sarmiento (1868-1874). Y en 1889 se llevó a cabo la creación del Ministerio de Agricultura. 
argentinos. En paralelo a que comenzaba a configurarse un marco legal regulador y normativo por el Estado, las primeras colecciones de semillas que denotaban esfuerzos deliberados de conservación en el país, fueron obra fundamentalmente de los criaderos privados (Pellegrini y Ballati, 2013).

En síntesis, la inserción capitalista de la agricultura de este país fue precoz y, por lo tanto, el comienzo de la mercantilización de las semillas también lo fue. En paralelo, la intervención del Estado también se dio de manera temprana. Se trató de un paso crucial en el cercamiento de las semillas, ya que apuntaba a incentivar la adopción de semillas mejoradas y ordenar el mercado mediante un sistema de fiscalización de la producción y de la comercialización. Por lo tanto, y en los términos en que lo planteamos en el apartado anterior (Bonnet, 2011), se trató de un proceso de incipiente mercantilización con estatalización.

\section{La Argentina como pionera: Revolución Verde y Ley de Semillas (1973)}

Al igual que lo ocurrido en el resto de América Latina, nuevas relaciones agrarias de producción fueron expandidas desde mediados de la década de 1950 a través de la denominada Revolución Verde. En Argentina esto se cristalizó durante el gobierno de Arturo Frondizi (1958-1962) que promovió el desarrollo tecnológico del agro como forma de incrementar la oferta exportadora (Gras y Hernández, 2016). Sin embargo, la institucionalización de estas nuevas formas productivas ya había dado un paso significativo con el Instituto Nacional de Tecnología Agropecuaria (INTA) en 1956, creado por el Estado nacional a los fines de impulsar la creciente tecnificación del sistema de producción agraria (Gárgano, 2013).

Esto significó un importante impulso para la investigación y el desarrollo en mejoramiento genético debido al desarrollo de semillas híbridas y la introducción de germoplasma extranjero, donde el INTA funcionó durante este período como el agente principal en el desarrollo de la genética aplicada a la producción agrícola en el país (Filomeno, 2012). En este marco, se introdujeron en el país trigos enanos (o mexicanos); se realizaron trabajos sistemáticos de fitomejoramiento de soja convencional; se promovió el uso masivo de fertilizantes; se creó el primer banco nacional de germoplasma con ambiente regulado ${ }^{6}$ y se realizó la recolección de material genético de maíz, maní y papa en centros de origen en Argentina.

Durante este período, la experimentación genética de cultivos fue mayoritariamente realizada por instituciones públicas y el Estado cumplió un rol importante en el financiamiento de organismos e investigaciones. Sin embargo, el impacto creciente de la utilización de semillas mejoradas que comenzó a hacerse sentir sobre la productividad agrícola, irá acompañado también por el crecimiento del sector privado en ciertas áreas del mejoramiento vegetal. Este crecimiento no puede comprenderse en profundidad si no tenemos en cuenta dos acontecimientos de gran importancia (Hendel, 2010): 1. el establecimiento del régimen de pedigree cerrado para los criaderos privados, según Resolución Ministerial Nº 841 de 1959. A partir de ese momento dejó de ser necesario revelar las fórmulas híbridas y fiscalizar los lotes de semilla parental, estableciendo una forma de protección de los DPI conocida como secretos industriales o comerciales; y 2. la declaración de utilidad pública de las líneas endocriadas en 1962, que constituían los híbridos descubiertos por los organismos públicos. Esto implicó que comenzara a regir

6 Se trató de la creación del Banco de Germoplasma de Maíz en la Estación Experimental de Pergamino (PeIlegrini y Ballati, 2013). 
el régimen de pedigree abierto para las instituciones públicas, con lo cual estas debían revelar sus fórmulas, fiscalizar los lotes de semilla parental y ceder las líneas endocriadas a quien lo solicitara, ya que eran considerados bienes públicos. De este modo, se crearon las condiciones para la apropiación privada de creaciones públicas y el desarrollo de la industria semillera en materia de híbridos, a costa de una enorme pérdida de capacidad de intervención por parte del Estado.

A partir de mediados de la década de 1960 se fueron configurando dos segmentos diferenciados: por un lado, el de los híbridos, abastecido sobre todo por empresas privadas transnacionales que en su gran mayoría, comenzaron a interesarse en el mercado argentino de híbridos de maíz; por el otro, el de las semillas autógamas en el cual participaba principalmente el INTA y empresas nacionales (Ceverio, 2006).

En términos globales, el sustento jurídico de la Revolución Verde fue la creación de las Leyes de Semillas, que hacen referencia a las reglamentaciones en torno a la regulación de la certificación, la fiscalización y la comercialización de semillas; esto es, qué materiales pueden venderse en el mercado y bajo qué condiciones (Felicien, 2016). Para la misma época, el principio de libre acceso a los materiales vegetales utilizados para el mejoramiento genético comenzó a resquebrajarse con el nacimiento en 1961 de la UPOV (Unión para la Protección de Obtenciones Vegetales), entidad que institucionalizó los DOV a nivel internacional7. La versión de 1978 contempla implícitamente el derecho de los agricultores. Esto significa que las agricultoras y los agricultores conservan el derecho a producir libremente sus semillas y pueden utilizar el producto de su propia cosecha, siempre que no sea para la venta. Es lo que se conoce como el uso propio de las semillas.

De esta manera, la configuración de la agricultura local, sumada a la influencia de los cambios globales respecto de los DPI sobre variedades de plantas y la necesidad de introducir más representantes del sector privado, fueron allanando el camino para la aparición de un debate que planteara la necesidad de modernizar la legislación vigente, que era considerada insuficiente (Gutiérrez, 1984). La Ley de Semillas y Creaciones Fitogenéticas N²0.247 fue promulgada el 30 de marzo de 1973, bajo el Gobierno dictatorial del Dr. Gral. Alejandro Lanusse. Ese mismo año se creó la Comisión Nacional de Semillas (CONASE). Sin embargo, la regulación recién se realizó en 1978, durante el gobierno militar que se extendió entre los años 1976 y 1983.

Se trata de una legislación de gran alcance que articula en el mismo cuerpo dos elementos que en muchos países se encuentran separados: se trata de una Ley de semillas clásica, que regula la producción, la certificación y la comercialización de todas las semillas del país; y es una legislación para la protección de los DPI de los cultivares. Asimismo, contempla las excepciones que están presentes en UPOV hasta su versión 78: la excepción de los fitomejoradores ya que menciona que no se requiere el consentimiento del obtentor de una variedad vegetal para utilizarla como insumo de investigación a los fines de obtención de otras variedades vegetales; y el derecho de los agricultores mediante el cual:

No lesiona el derecho de propiedad sobre un cultivar quien entrega a cualquier título semilla del mismo mediando autorización del propietario, o quien reserva y siembra semilla para su propio uso, o usa o vende como materia prima o alimento el producto obtenido del cultivo de tal creación Fitogenética. (Ley de Semillas y Creaciones Fitogenéticas, No 20.247, Art. 27)

7 El Convenio UPOV se reformuló en tres oportunidades: 1972, 1978 y 1991. 
La definitiva profundización de la Revolución Verde se dio durante la dictadura militar (1976-1983) cuando la expansión agropecuaria comenzó a articularse a la especulación financiera en el contexto de transformaciones en el patrón de acumulación local (Azpiazu y Schorr, 2010). Un tema central fue la profundización de la privatización del conocimiento en el ámbito de la investigación pública donde el caso del INTA fue paradigmático ya que al tiempo que se introducían fuertes mecanismos represivos, sufrió un recorte en su financiamiento o presupuesto y la pérdida de su autarquía financiera, con los consecuentes impactos negativos sobre su funcionamiento. En un contexto de incremento en la apropiación privada de su trabajo científico y técnico, que favoreció la consolidación de los sectores más concentrados del agro (Gárgano, 2013) el banco de semillas que poseía el INTA sufrió un fuerte retroceso y parte del acervo genético de la biodiversidad local pasó a estar en manos de las empresas trasnacionales que ingresaban al país (Teubal y Palmisano, 2010).

De esta manera, podemos visualizar una primera etapa durante este periodo asociada al ingreso del sector público en la labor de mejoramiento y conservación de semillas (Clausen, Ferrer, Gómez y Tillería, 1995). Sin embargo, a partir de mediados de la década de 1970 el papel del Estado como productor de conocimientos, promotor de proyectos y financiador de la investigación comenzó a debilitarse paulatinamente, y los esfuerzos se reorientaron a promover un marco legal que garantizase los incentivos para el sector privado. La nueva concepción del Estado, en línea con el modelo neoliberal que comenzaba a instaurarse, exigió que también las instituciones públicas de investigación asumieran riesgos y mecanismos de incentivos típicos de la economía de mercado.

\section{LA DÉCADA DE 1990: LA BIOTECNOLOGÍA AGRARIA ENTRA EN ESCENA (1991-2002)}

Los profundos cambios generados durante la década de 1990 tuvieron lugar también en las regiones agrarias. Durante este período se consolidó el modelo agrario iniciado con la Revolución Verde entrando en escena los agronegocios (Gras y Hernández, 2013; 2016). La biotecnología agraria (en este caso la soja transgénica y el paquete que la acompaña) se consolidó como el epicentro de la valorización en el agro argentino.

Los comienzos de la década de 1990 fueron clave con varios acontecimientos que cambiaron radicalmente el rumbo del panorama agrario argentino. El primero de ellos, remite a la política de desregulación de la economía iniciada en 1991, que se concretó a partir del Decreto N²248/91 y que desarmó todo el andamiaje institucional que había sostenido el modelo de desarrollo agropecuario desde las décadas anteriores. Esto llevó al cierre, entre otras, de las Juntas Nacionales de Carne (1991) y Granos (1992) y la cuasi eliminación de las políticas activas de intervención estatal en la economía agraria.

El segundo acontecimiento fue la creación de la Comisión Nacional de Biotecnología Agropecuaria (CONABIA) también en 1991. Fue creada bajo la órbita de la Secretaría de Agricultura, Ganadería Pesca y Alimentación (SAGPyA) en el Ministerio de Economía y concebida con el fin de crear el marco regulatorio para la formulación e implementación de políticas en torno a la liberación, producción y comercialización de Organismos Genéticamente Modificados (OGM). Desde sus orígenes, el organismo se compuso con lo que se denominan expertos tanto del ámbito público como del privado, con un perfil eminentemente científico ${ }^{8}$.

8 Fueron parte de su composición original: Integrantes del sistema científico (INTA, Universidad de Buenos Aires-UBA y el Consejo Nacional de Investigaciones Científicas y Técnicas-CONICET); representantes del sector 
Finalmente, el tercer acontecimiento fue la liberalización de la soja transgénica en 1996. La SAGPyA le otorgó la licencia a Monsanto para comercializar la soja RR (Roundup Ready) junto al glifosato, herbicida al cual el cultivo es resistente. Se trató de la incorporación de insumos relativamente baratos (semillas y herbicidas), especialmente porque no incluía pago alguno en concepto de regalías por el uso del gen RR ya que Monsanto en Argentina no obtuvo la patente (Campi, 2013). Hacia fines de la década de 1990, este cultivo se encontraba masificado y con muchos productores y empresas utilizando el paquete tecnológico necesario para cultivar soja transgénica: semillas, herbicidas y maquinaria para sembrar y cosechar soja.

En 2001 la economía argentina colapsó cuando la paridad entre el peso y el dólar (instalada en 1991) se volvió insostenible y el país tuvo problemas para pagar los préstamos extranjeros. En medio de una profunda crisis económica, política y social, el gobierno devaluó el peso. Esto además del aumento de los precios internacionales de los productos de exportación, convirtió a la agricultura en una actividad aún más importante para la economía argentina como proveedor de divisas. Durante este período, la soja RR y el modelo que la acompaña, se expandió agresivamente hacia zonas extra pampeanas reforzando una tendencia hacia el monocultivo, la concentración económica y el desplazamiento de la producción de alimentos (Teubal, Domínguez y Sabatino 2005).

La denominada revolución biotecnológica trajo también cambios sustanciales en las formas de apropiación de las semillas. Hasta la década de 1980 las patentes sobre organismos vivos no estaban permitidas. Sin embargo, el fallo Diamond-Chakrabarty de la Corte Suprema de Estados Unidos, admitió una patente sobre una bacteria modificada capaz de separar los componentes de petróleo crudo, constituyendo una bisagra al delimitar lo que es patentable y lo que no (Pérez Miranda, 2002).

En la década de 1990 se dio un proceso de profundización de los DPI: se creó en 1995 la Organización Mundial del Comercio (OMC) con sus nuevos temas comerciales que dio lugar al Acuerdo sobre los Aspectos de los Derechos de Propiedad Intelectual relacionados con el Comercio (ADPIC); la UPOV fue modificada en 1991, recortando los derechos de los agricultores sobre sus semillas y se extendió la firma de tratados de libre comercio, en los que los DPI adquieren gran protagonismo.

Estas transformaciones globales tuvieron su correlato en la modificación de legislaciones nacionales ( $y$ muchas están aún en proceso de discusión) para adecuarlas a las nuevas directrices del comercio mundial de semillas (Perelmuter, 2011). Así, Argentina dio algunos pasos importantes para adaptarse a los cambios que se estaban dando en términos globales en relación al cercamiento jurídico.

El Reglamento de la Ley de Semillas y Creaciones Fitogenéticas se modificó en 1991 a partir del Decreto $N^{\circ} 2.183$, ante una fuerte presión política ejercida por la Asociación de Semilleros Argentinos (ASA), la Asociación Argentina de Protección de Obtenciones Vegetales (ARPOV) y otros grupos de interés dentro de CONASE para reforzar el peso del sector privado (Filomeno, 2012). No se tocaron las excepciones, por lo tanto, la reglamentación reafirma el derecho de los productores a guardar y replantar semillas

público (Dirección Nacional de Producción y Comercialización Agrícola, Servicio Nacional de Sanidad y Calidad Agroalimentaria-SENASA, Dirección Nacional de Producción Agropecuaria); y representantes del sector privado (Foro Argentino de Biotecnología y Asociación de Semilleros Argentina-ASA). Todos poseían una formación académica en estos temas. Si bien a lo largo de la existencia de la comisión se fueron incorporando representantes de otras instituciones del sector público y el privado, la continuidad del perfil científico y la expertise se mantuvieron constantes a lo largo de su existencia (Poth, 2013). 
de sus propios campos sin el consentimiento de los propietarios de los cultivares. Asimismo, la modificación del Reglamento fue parte de una estrategia orientada a reforzar los DPI aplicados a variedades vegetales, en la cual confluyó otro acontecimiento: la adhesión de Argentina a UPOV 78 en 1994 a través de la Ley $N^{\circ} 24.376^{9}$.

Como podemos visualizar, el caso del Estado neoliberal es un claro ejemplo de mercantilización con des-estatalización de las relaciones sociales. Pero de ninguna manera significó la existencia de un Estado mínimo o ausente, como muchas veces fue caracterizado (Oszlak, 2000).

Las privatizaciones y concesiones a empresas públicas, así como las políticas desregulación del mercado doméstico y de apertura al mercado mundial, implicaron efectivamente una mercantilización con des-estatalización de las relaciones sociales, pero esto no condujo ni a un debilitamiento del estado argentino -como estado capitalista, es decir como modo de existencia de una relación de dominación de clase, el estado neoliberal es un estado fuerte- ni siquiera a un achicamiento del estado - a la luz de su presupuesto, personal, dependencias o cualquier otro criterio, el estado neoliberal suele ser tanto o más grande que otras forma de estado anteriores. (Bonnet, 2011, p. 27)

Para Ouviña (2002), el rol asumido por el Estado en este periodo fue el de facilitar la expansión en el espacio territorial nacional de los mecanismos de mercado desplegados a nivel global. Por lo tanto, más que una minimización del Estado ante el avance del mercado, se trató de una metamorfosis del primero, de una transformación de sus funciones. Porque para que el mercado pudiera sostener su funcionamiento y expandir su lógica, el Estado tomó decisiones en esa dirección.

Para nuestro caso de análisis, la hegemonía de las políticas neoliberales se evidenció también en la desinversión en ciencia y tecnología que llevó a una profunda crisis del sistema nacional de investigación. Por lo tanto, esa metamorfosis del Estado, esa transformación de sus funciones, se tradujo en las políticas agrarias, con la consolidación del modelo de agronegocios; y en la expansión de políticas públicas que impulsaron el maridaje entre la ciencia y el mercado (Gras y Hernández, 2016).

KIRCHNERISMO: LOS INTENTOS POR LEGITIMACIÓN Y EL DEBATE POR EL USO PROPIO (2003-2015)

Los comienzos del siglo XXI en América Latina implicaron cierta reacción cuestionadora de la primacía de la lógica mercantil por sobre la voluntad política, y por lo tanto, volvió a considerarse al Estado como un actor relevante. Se trató del surgimiento de una variedad de procesos políticos cuyo denominador común fue la compartida crítica al conjunto de ajustes y reformas estructurales llevados a cabo en la previa década de 1990. Los discursos, y en parte las prácticas, de los nuevos gobiernos estuvieron marcados por la recuperación del papel del Estado en materia de políticas económicas y sociales, constituyéndose la iniciativa estatal en la principal promotora de los lineamientos de las nuevas orientaciones políticas. En este trabajo lo caracterizamos, siguiendo a Thwaites Rey y Ouviña (2018) como Ciclo de Impugnación al Neoliberalismo (CINAL), que permite expresar su carácter fluido, heterogéneo y en disputa.

Durante los gobiernos de Néstor Kirchner (2003-2007) y Cristina Fernández de Kirchner (2007-2015), el Estado promovió la biotecnología agraria, y se consolidaron los agronegocios a través de leyes y reglamentos y políticas de ciencia y tecnología. En paralelo, los intentos por modificar la Ley de Semillas se intensificaron.

9 Los trámites para la adhesión se realizaron bajo la gestión de Regúnaga en la SAGPyA a partir de 1991, pero la finalización se realizó en 1994 bajo la gestión de Felipe Solá, quien estuvo entre 1993 y 1999 en dicha Secretaría. 
Si bien CONABIA aprobó 35 eventos transgénicos entre 1996 y 2015, el 80\% de ellos (28) fueron aprobados después de $2003^{10}$. En 2015 se aprobaron dos cultivos transgénicos desarrollados en la Argentina en una clara articulación público-privada: uno es un gen que le permitirá a las variedades de soja crecer en terrenos con escasez de agua, en la jerga conocidos como resistente al estrés hídrico desarrollada por un equipo de científicos liderado por la doctora Raquel Chan, de la Universidad del Litoral. La licencia de uso y explotación está en manos del Instituto Nacional de Agrobiotecnología de Rosario (INDEAR); y el segundo, es una tecnología que le garantizará a la papa inmunidad ante un virus denominado PVY, invento que corrió directamente por cuenta del CONICET y será comercializado por Tecnoplant, del grupo Sidus.

Las políticas del MINCyT (Ministerio de Ciencia y Tecnología) son otro ejemplo de promoción a la biotecnología. El organismo sancionó un nuevo Plan Estratégico para el Desarrollo de la Biotecnología Agrícola 2005-2015 para promover la creación y difusión de semillas transgénicas a través de la cooperación público-privada, generar un marco regulatorio favorable para los OGM y estimular en general el desarrollo de biotecnología en Argentina.

El apoyo brindado a los agronegocios durante este período también se puede ver en el Plan Estratégico Agroalimentario 2010-2020 (PEA), lanzado por el gobierno en 2011. Este plan propuso expandir la producción de soja transgénica para alcanzar una cosecha de 160 millones de toneladas para 2020. Esto implicaría la incorporación de 11 millones de nuevas hectáreas a la tierra cultivable existente con la consecuente profundización de los problemas asociados con la expansión de la frontera de la soja (Lapegna 2017).

Durante este periodo se construyó lo que denominamos una política dual y contradictoria entre el agronegocio y la agricultura familiar. Una dualidad claramente que no fue simétrica (Perelmuter, 2018). El denominado conflicto del campo ${ }^{11}$, desatado tras la divulgación de la Resolución N 125/08 del Ministerio de Economía que pretendía establecer retenciones móviles, y la forma en que este se resolvió, significó un rediseño de las políticas de desarrollo rural. Esto tuvo como objetivo generar cierta regulación sobre la actividad agropecuaria y revertir algunos de los impactos negativos derivados del avance de los agronegocios, que el mismo gobierno alentaba. Durante el transcurso del año 2008 se creó una Subsecretaría de Desarrollo Rural y Agricultura Familiar. Un año más tarde, cuando la SAGPyA (Secretaría de Agricultura, Ganadería, Pesca y Alimentos) pasó a ser Ministerio de Agricultura, Ganadería y Pesca (MAGyP), la Subsecretaría se constituyó en Secretaría de Desarrollo Rural y Agricultura Familiar. En 2014 se sancionó la Ley de Reparación histórica de la agricultura familiar para la construcción de una nueva ruralidad en la Argentina (Ley N²7.118), una iniciativa gubernamental que tomó

10 De estos, dieciocho corresponden a maíces, siete a soja, dos a algodón y uno a papa. De este grupo de 28 OGM comerciales, Monsanto ha sido el solicitante en un tercio de los casos, seguido por Syngenta, Dow Agrosciences, Basfy Bayer.

11 El conflicto comenzó a partir de la Resolución N 125/08 que establecía un sistema de retenciones móviles que implicaban una indexación de los porcentajes de retención de acuerdo al precio internacional de los commodities de origen agrario aumentando el gravamen que pagaban los productores por sus exportaciones. El rechazo a la medida generó diversas manifestaciones por parte de la denominada Mesa de Enlace (Federación Agraria Argentina-FAA, Confederaciones Rurales de la República Argentina-CRA, la Sociedad Rural Argentina-SRA y CONINAGRO) que fueron desde los cortes de ruta hasta un lockout patronal que implicó un desabastecimiento de alimentos en las ciudades. Cinco meses después de iniciado el conflicto, el proyecto fue discutido en el Congreso, donde tras una votación empatada el Vicepresidente Julio Cobos, con su voto, rechazó la aprobación de la ley llevando las retenciones nuevamente al estado en el que se encontraban antes del conflicto. 
un reclamo histórico de las organizaciones campesinas y de la agricultura familiar ${ }^{12}$. La Ley nunca fue reglamentada y por lo tanto, no se puso en vigencia.

En relación al cercamiento jurídico de las semillas, desde comienzos del siglo XXI se suscitaron una serie de iniciativas gubernamentales tendientes a la modificación de la legislación de semillas (Casella, 2005). A partir de 2012 esta discusión tomó un impulso importante y se abrió una mesa de negociaciones en el marco de la CONASE (Comisión Nacional de Semillas), de la que participaron miembros de organismos públicos ${ }^{13}$, del sector privado ${ }^{14} y$ de las entidades de productores agrarios ${ }^{15}$. Ni las organizaciones campesinas e indígenas, ni aquellas relacionadas con la denominada agricultura familiar, ni las universidades nacionales y los organismos públicos de investigación como el CONICET, fueron consultados ni incorporados formalmente al debate. La Federación Agraria Argentina (FAA) formuló su rechazo y se retiró de la mesa de negociaciones.

El anteproyecto denominado Proyecto INASE 2012 (Rapela, 2016) nunca fue divulgado y puesto a consideración oficialmente para el debate público, pero sí fue filtrado. Sin hacerlo explícito, las versiones en cuestión tomaban algunos elementos de UPOV 91: se buscaba restringir el uso propio e incrementar sanciones, otorgando a las empresas el poder de policía para controlar y fiscalizar los campos en el caso de que se presumiera que la ley no se cumplía. Esto generó el rechazo por parte de organizaciones sociales, políticas (incluso algunas que eran afines al gobierno), campesinas, indígenas y de la agricultura familiar (Perelmuter, 2017).

Hacia fines del periodo analizado, las negociaciones se estancaron y los proyectos oficiales no salieron de la Comisión Nacional de Semillas (CONASE). Por lo tanto, ningún proyecto oficial entró al Congreso y los presentados por las bancadas opositoras nunca fueron discutidos.

La postura del Estado entre 2012 y 2015 no estuvo exenta de tensiones. Por un lado, el impulso hacia la posible modificación vino por parte del Ministerio de Agricultura. La Presidenta Cristina Fernández de Kirchner dio muestras de querer avanzar en el debate (Filardi, 2014) ${ }^{16}$. Pero por otro lado, hubo sectores al interior del mismo Ministerio que se posicionaron de manera contraria, como el caso de quien fue el Secretario de Agricultura Familiar, Emilio Pérsico (Bertello, 2012; 2014).

En síntesis, lo que se evidenció durante este periodo fue una clara consolidación de la biotecnología como área científica clave para el Estado nacional, en el marco de la

12 Entre los puntos más significativos, se destaca que la norma considera a la tierra como bien social y crea un Banco de Tierras; se promueve una suspensión de los desalojos por tres años y genera una Comisión Nacional Permanente de Regularización Dominial de la Tierra Rural; prevé la promoción de las ferias locales, zonales y nacionales de la agricultura familiar para apoyar el contacto directo entre productores y consumidores; y genera el Centro de Producción de Semillas Nativas (CEPROSENA), introduciendo un nuevo elemento a la discusión sobre las semillas en Argentina.

13 Participaron el INTA (Instituto Nacional de Tecnología Agropecuaria), el INASE (Instituto Nacional de Semillas) y el Ministerio de Agricultura, Ganadería y Pesca.

14 Participaron ASA (Asociación de Semilleros Argentinos); CASEM (Cámara Argentina de Semilleros Multiplicadores); AACREA (Asociación Argentina de Consorcios Regionales de Experimentación Agrícola) y AAPRESID (Asociación de Productores de Siembra Directa).

15 Las entidades en cuestión son FAA (Federación Agraria Argentina), SRA (Sociedad Rural Argentina), CONINAGRO (Confederación Intercooperativa Agropecuaria) y CRA (Confederaciones Rurales Argentinas).

16 Esto quedó registrado en los Wikileaks, que a su vez dejan entrever las fuertes presiones realizadas, no solo por Monsanto, sino sobre todo por la embajada de Estados Unidos, para avanzar hacia un nuevo régimen de DPI en semillas en la Argentina (Filardi, 2014). 
recuperación del Estado. Pero lo novedoso vino de la mano de estrategias de investigación tecnológica conjuntas con algunos actores privados. Este tipo de estrategias se despliegan a partir de alianzas en las que el sector privado asume un papel central en la coordinación de los organismos públicos participantes, los cuales tienen escasa o nula experiencia de articulaciones entre sí.

\section{El cercamiento de las Semillas en tiempos de Cambiemos (2016-2019)}

Un nuevo momento se inició en 2016 con la asunción del Gobierno de Cambiemos y que implicó un cambio de etapa política. Desde su asunción, se tomaron múltiples medidas que marcaron una profundización de los agronegocios, al tiempo que el debate por la apropiación de las semillas se intensificó.

La política agraria del macrismo no fue improvisada: gran parte de ella quedó plasmada en la Propuesta de Política Agroindustrial 2015-2019 que fue elaborada por especialistas del PRO junto a la Fundación Pensar. Si bien los trece puntos allí consignados no fueron aplicados en su totalidad, muchas de las medidas del nuevo gobierno orientadas al sector estaban en ese documento: eliminación de retenciones (impuesto a la exportación) para los productos agropecuarios y la reducción de cinco puntos a la soja (pasó del $35 \%$ al 30\%) que generó una transferencia de recursos al sector más concentrado; y cambio del nombre del ministerio al de Agroindustria, marcando cuál es la concepción que se tiene de la agricultura (Agrovoz, 23/11/2005). Asimismo, se aprobaron veinte nuevos transgénicos de soja, maíz, algodón, alfalfa y cártamo. Las principales empresas beneficiadas fueron Syngenta, Dow Agrosciences, Pioneer y Monsanto. Pero también aparece INDEAR en algunos casos.

Asimismo, mientras se profundizaron los agronegocios el gobierno avanzó sin miramientos sobre la desarticulación del área de agricultura familiar, parte del Ministerio de Agroindustria que a comienzos de septiembre de 2018 pasó a ser una secretaría dependiente de Producción.

Luego de varios años en que se discutía la posibilidad de modificar la Ley de Semillas pero no se presentaba de manera formal ningún anteproyecto, en octubre de 2016 el gobierno de Mauricio Macri, presentó su propuesta luego de varios meses de negociaciones en secreto. Algunos sectores de la oposición política también presentaron proyectos. Pero la gran novedad fue la presentación de propuestas por parte de una entidad de productores (FAA) y una cámara empresarial (ASA), que avanzaba mucho más en el recorte del uso propio que el proyecto del oficialismo al no plantear siquiera excepciones para el recorte del mismo (Perelmuter, 2017). Todos esos proyectos perdieron estado parlamentario.

De manera simultánea, a mediados de 2016 se estableció mediante la Resolución No 207/16 el sistema Bolsa Tech, patrocinado por la Bolsa de Cereales de Buenos Aires consistente en establecer la trazabilidad de la información que se utiliza para los controles ${ }^{17}$. De esta manera, el Estado se hacía cargo de controlar el origen de las semillas, en defensa de los intereses de los llamados obtentores. La norma estuvo pensada solo para la campaña 2016/2017, ya que el Gobierno confiaba en que habría

17 Según consta en el primer artículo de la resolución N² 207: "Para la cosecha de soja Campaña 2015/16, le serán extraídas al productor o remitente muestras de grano en el primer punto de entrega las cuales podrán ser requeridas por el Instituto Nacional de Semillas, organismo descentralizado en la órbita del Ministerio de Agroindustria, para la verificación del cumplimiento de la Ley de Semillas y Creaciones Fitogenéticas Nº 20.247 (ley de semillas)”. 
una nueva ley de semillas para la campaña siguiente. Pero como esto no ocurrió, el sistema se extendió a la campaña 2017/2018.

En 2018, con negociaciones desarrolladas a puertas cerradas junto a las corporaciones empresariales (ASA, AACREA y AAPRESID) y algunas de las corporaciones de grandes productores (como la SRA, CONINAGRO y CRA), el gobierno aprobó un dictamen de la comisión de agricultura de la cámara de diputados sin el apoyo de ningún otro bloque político. El resultado fue un intenso y plural rechazo por parte de FAA, organizaciones campesinas, agrupaciones indígenas, productores y productoras de la agricultura familiar, así como movimientos sociales y ambientales. A finales de 2019 el dictamen perdió estado parlamentario.

Al igual que la mayoría de los anteproyectos y proyectos que estuvieron en debate desde 2012, la nueva legislación apuntaba a reglamentar y restringir el uso propio, remarcando que solo podrán hacer uso de esta prerrogativa los denominados agricultores exceptuados. Se trata de una concepción que entiende que el uso propio debe dejar de ser libre y gratuito, un derecho de los agricultores, para pasar a ser una mera excepción de un derecho que tienen otros: los obtentores. Esto implica un cambio radical en la forma en la que se concibe esta práctica histórica de las agricultoras y los agricultores.

Debido a que se trata de un proceso muy reciente, sería apresurado aseverar conclusiones en torno al cercamiento de las semillas durante este periodo. No obstante, consideramos que sí es posible arriesgar que se trató de un nuevo estadío de mercantilización con des-estatalización. Pero nuevamente, no se trata de un Estado ausente; sino de un Estado con una profunda orientación hacia el sector privado, con políticas públicas orientadas a tal fin.

\section{REFLEXIONES FINALES}

En este artículo nos propusimos analizar el cercamiento de las semillas en Argentina, prestando particular atención a las formas de dominación política y como estas se fueron reconfigurando. Por lo tanto, la mirada sobre el rol del Estado fue central. Nos centramos en cinco períodos históricos y en cada uno visualizamos de qué manera el Estado se posicionó en relación al mejoramiento, la conservación y la apropiación de las semillas. El objetivo fue identificar en cada momento los procesos de estatalización/ des-estatalización y de mercantilización/des-mercantilización.

Desde el surgimiento de la agricultura, las productoras y los productores rurales han recolectado, almacenado, conservado e intercambiado libremente las semillas, manteniendo el control de las mismas. Históricamente fueron consideradas bienes comunes (Perelmuter, 2011). Esto en la Argentina se dio a partir de la articulación de las semillas de las comunidades indígenas y campesinas, con aquellas traídas por los inmigrantes que comenzaron a llegar hacia fines del siglo XIX.

El primer periodo que analizamos lo interpretamos como de mercantilización con estatalización ya que el cercamiento de las semillas se dio de manera muy temprana. Pero también la intervención del Estado fue precoz mediante la sanción de la Ley de Granos y Elevadores en 1935.

Hubo un segundo momento importante: la Revolución Verde donde la experimentación genética de cultivos fue mayoritariamente realizada por instituciones públicas (sobresaliendo el papel del INTA). Por lo tanto, el Estado cumplió un rol importante en el financiamiento de organismos e investigaciones, sobre todo al comienzo del pe- 
riodo. Sin embargo, la actividad privada fue incorporando sucesivas restricciones que 'resguardaron' sus materiales. Fue en este contexto que se sancionó la Ley de Semillas y Creaciones Fitogenéticas en 1973 que en su justificación, le otorgaba al Estado un rol particular: impulsar la actividad privada de fitomejoramiento y garantizar los DPI para los fitomejoradores.

Esta situación se va a profundizar en la década de 1990 con la implementación sistemática del neoliberalismo y de los agronegocios. Como ya mencionamos, en este caso se trató de una profunda mercantilización con des-estatalización de las relaciones sociales. Pero para que el mercado pueda sostener su funcionamiento y expandir su lógica, el Estado tomó decisiones que tendieron a eso: medidas concretas para la implementación de los agronegocios y la consolidación de la biotecnología agraria; desinversión en ciencia y tecnología que llevó a una profunda crisis del sistema nacional de investigación; y al mismo tiempo, el Estado ajustó los DPI de modo que los activos intangibles pudieran ser valorizados como mercancías.

A partir del año 2003 comienza un nuevo período que caracterizamos como de consolidación de los agronegocios y la construcción de nuevos 'consensos'. Esto vino de la mano de una recuperación del rol del Estado, sobre todo en relación a las políticas orientadas a la promoción de la ciencia y tecnología (C\&T), y en la segunda etapa del periodo (luego del 2008), una política activa hacia el fortalecimiento de la agricultura familiar. En paralelo, los intentos por modificar la Ley de Semillas se intensificaron. Lo que se evidenció fue una clara consolidación de la biotecnología como área científica clave para el Estado nacional. Por lo tanto, identificamos a este periodo como de mercantilización con estatalización, pero lo novedoso es que esta 'recuperación del Estado' vino de la mano de estrategias de investigación tecnológica conjuntas con algunos actores privados.

Finalmente, identificamos como un nuevo estadío de mercantilización con des-estatalización a lo ocurrido entre los años 2015-2019, con intentos sistemáticos por avanzar en el cercamiento de las semillas. Pero como podemos visualizar, el Estado ejecutó políticas activas orientadas a fortalecer el sector privado.

En síntesis, del análisis del proceso de cercamiento de las semillas en la Argentina podemos inferir que esto implicó, aunque no de manera lineal, el pasaje de lo común a lo público, y luego a lo privado. Pero aún en los momentos donde el rol de lo privado se intensificó, el Estado cumplió un rol activo en todos los períodos.

Si bien en este artículo analizamos el temprano cercamiento de las semillas en la Argentina, tanto agrario como jurídico, entendemos que este proceso se aceleró con la crisis de la década de 1970. Nos encontramos, en palabras de Harvey (2004), ante un nuevo ciclo de acumulación por desposesión, nuevo movimiento de la expansión del capital que se sustenta en base a una nueva composición tecnológica del proceso de producción, y donde identificamos que la biotecnología cumple un rol fundamental. En ese marco, las empresas biotecnológicas identificaron el enorme valor que tienen las semillas en el control de la agricultura mundial. Son conscientes de que quien controle las semillas y sus paquetes tecnológicos asociados, va a controlar los sectores productivos y el sistema alimentario. Y a nadie escapa lo que significa tener el control de los alimentos.

Pero, a su vez, visualizamos que ni el cercamiento de las semillas ni el rol del Estado para que eso ocurriera, se dieron de manera lineal. Si bien es cierto que las presiones para profundizar el cercamiento se intensificaron, no estuvieron exentas de conflictos y tensiones, atravesadas por luchas y dinámicas sociales. Por lo tanto, el debate por la 
profundización (o no) del cercamiento está abierto, y las semillas en Argentina son un elemento de debate y múltiples disputas.

\section{REFERENCIAS}

Agrovoz (23/11/2005). Las 13 políticas que promete Macri para reactivar la agroindustria. Recuperado de http://agrovoz.lavoz.com.ar/actualidad/las-13-politicas-que-promete-macri-para-reactivar-la-agroindustria

Azpiazu, D. y Schorr, M. (2010). Hecho en Argentina. Industria y economía, 1976-2007. Buenos Aires: Siglo XXI Editores.

Beck, U. (1998). ¿Qué es la globalización? Barcelona: Paidós.

Bertello, F. (2012). Posturas. La propiedad intelectual de las semillas divide al Gobierno. Diario La Nación. Recuperado de http://www.lanacion.com.ar/1529112-la-propiedad-intelectual-de-las-semillas-divide-al-gobierno;

Bertello, F. (2014). Puja. Tensión entre Casamiquela y Pérsico en Agricultura. Diario La Nación. Recuperado de http://www.lanacion.com.ar/1690714-tension-entre-casamiquela-y-persico-en-agricultura

Bonefeld, W. (2001). The permanence of primitive accumulation: commodity fetishism and social constitution. The Commoner, (2), 1-15.

Bonnet, A. (2011). Las relaciones entre estado y mercado: ¿un juego de suma cero? (pp. 15-44). En A. Bonnet (Comp.) El país invisible. Debates sobre la Argentina reciente. Buenos. Aires: Peña Lillo/Continente.

Boyle, J. (2003). The second enclosure movement and the construction of the public domain. Recuperado de https://scholarship.law.duke.edu/cgi/viewcontent.cgi?article=1273\&context $=I_{c p}$ (consulta 15 de agosto de 2020).

Campi M. (2013). Tecnología y Desarrollo Agrario. En G. Anlló, R. Bisang y M. Campi (Coords.) Claves para repensar el agro argentino. Buenos Aires: EUDEBA.

Casella, A. (2005). Federación agraria profundiza en contenidos (pp. 55-175). En Un país que resigna soberanía. Patentamiento y regalías en semillas. Buenos Aires: Editorial Federación Agraria Argentina.

Ceverio, R. (2006). Derechos de propiedad intelectual en el mercado argentino de semillas de trigo y soja. Tesis maestría. Universidad Nacional de Mar del Plata.

Clausen, A.M.; Ferrer, M.E.; Gómez, S. y Tillería, J. (1995). Argentina: Informe nacional para la conferencia técnica internacional de la FAO sobre los recursos fitogenéticos. Recuperado de http:// www.fao.org/pgrfa-gpa-archive/arg/argentina.pdf (consulta 22 de diciembre de 2019).

Cleaver, H. (1972). The contradictions of the Green Revolution. Recuperado de http://www.eco. utexas.edu/ hmcleave/cleavercontradictions.pdf (consulta 22 de diciembre de 2019).

Dalla Costa, M. (2004). Capitalism and Reproduction. The Commoner, (8). Recuperado de https://thecommoner.org/wp-content/uploads/2020/06/Mariarosa-Dalla-Costa-Capitalism-and-Reproduction.pdf (consulta 22 de diciembre de 2019).

De Angelis, M. (2001). Marx and primitive accumulation: The continuous character of capital's enclosures. The Commoner, (2), 1-22.

Felicien, A. (2016). Historia de las Leyes de semillas y la modernidad en la agricultura (pp. 21-46). En Semillas del pueblo. Luchas y resistencias para el resguardo y reproducción de la vida. Caracas: Fundación Editorial El perro y la rana. 
Filardi M. (2014). Semillas, derecho a la alimentación adecuada y soberanía alimentaria. Realidad Económica, (288).

Filomeno, F. (2012). The social basis of intellectual property regimes: biotechnology in South American soybean agricultura. Tesis doctoral. Universidad Johns Hopkins, Baltimore, Maryland.

Flichman, G. (1977). La renta del suelo y el desarrollo agrario argentino. Buenos Aires: Siglo XXI.

Gárgano, C. (2013). Ciencia y Dictadura: producción pública y apropiación privada de conocimiento científico-tecnológico. Dinámicas de cooptación y transferencia en el ámbito del Instituto Nacional de Tecnología Agropecuaria (INTA) durante la última dictadura cívico militar argentina (1976-1983). Crítica y Emancipación. Revista latinoamericana de Ciencias Sociales, (10), 131-170.

Gilly, A. y Roux, R. (2009). Capitales, tecnologías y mundos de la vida. El despojo de los cuatro elementos (pp. 27-52). En Los condicionantes de la crisis en América Latina. Inserción internacional y modalidades de acumulación. Buenos Aires: CLACSO.

Gras, C. y Hernández, V. (2013). El modelo de agribusiness y sus traducciones territoriales (pp. 49-66). En C. Gras y V. Hernández (Coords.) El agro como negocio. Producción, sociedad y territorios en la globalización. Buenos Aires: Editorial Biblos.

Gras, C. y Hernández, V. (2016). Radiografía del nuevo campo argentino. Del terrateniente al empresario transnacional. Buenos Aires: Siglo XXI Editores.

Gutiérrez, M. (1984). Reflexiones sobre la legislación que regula el mejoramiento varietal y la industria de semillas en la Argentina. Documento PROAGRO No 8. Buenos Aires: CISEA.

Gutiérrez, M. y Penna, J. (2004). Derechos de obtentor y estrategias de marketing en la generación de variedades públicas y privadas. Documento de Trabajo No 31. Buenos Aires: Instituto Nacional de Tecnología Agropecuaria.

Harries, A. y Ripoll, C. (1998). Evolución del fitomejoramiento y la producción de semillas en nuestro país. Estructuras oficiales y su marco regulatorio desde comienzos de siglo. Buenos Aires: Sagpya.

Harvey, D. (2004). El 'nuevo' imperialismo: acumulación por desposesión. Socialist Register, 99-129.

Hendel, V. (2010). Genealogía de la semilla. Regulación y escasez en la región pampeana de la Argentina. Nómadas. Revista Crítica de Ciencias Sociales y Jurídicas, (27), 351-367.

Hirsch (1978). The State Apparatus and Social Reproduction: Elements of a Theory of the Bourgeois State. En J. Holloway y S. Picciotto (Comps.) State and Capital. A Marxist Debate. Londres: Edward Arnold.

Holloway, J. y Picciotto, S. (1980). La teoría marxista de la crisis, del capital y del Estado. En Estado y economía, crisis permanente del Estado capitalista. Bogotá: Sociedad de Ediciones Internacionales.

Holloway, J. (1994). Marxismo, Estado y Capital. Buenos Aires: Editorial Tierra del Fuego.

Kloppenburg, J. (2005). First the seed: the political economy of plant biotechnology (2. ${ }^{\text {a edición). }}$ Madison: University of Wisconsin Press

Lapegna, P. (2017). The Political Economy of the Agro-export Boom under the Kirchners: Hegemony and Passive Revolution in Argentina. Journal of Agrarian Change, 17(2), 313-329.

Leguizamón, A. (2020). Seeds of Power: Environmental Injustice and Genetically Modified Soybeans in Argentina. Durham, NC: Duke University Press.

López Monja, C.; Poth, C. y Perelmuter, T. (2010). El avance de la soja transgénica, ¿progreso científico o mercantilización de la vida? Un análisis crítico a la biotecnología agraria en Argentina. Buenos Aires: Ediciones Centro Cultural de la Cooperación. 
Luxemburgo, R. (2007). La acumulación del Capital. La Plata: Terramar.

Marx, K. (2000). El capital: crítica de la economía política. México: Fondo de Cultura Económica.

Motta, R. (2016). Social Mobilization, Global Capitalism and Struggles over Food: A Comparative Study of Social Movements. New York: Routledge.

O’ Donnell, G. (1984). Apuntes para una teoría del Estado. En Teorías críticas de la burocracia estatal. Buenos Aires: Editorial Paidós.

Osorio, J. (2014). Estado, reproducción del capital y lucha de clases : la unidad económico/política del capital. México: Universidad Nacional Autónoma de México, Instituto de Investigaciones Económicas.

Oszlak, O. (2000). El mito del Estado mínimo: una década de reforma estatal en Argentina. V Congreso Internacional del CLAD sobre la Reforma del Estado y de la Administración Pública. Santo Domingo.

Ouviña, H. (2002). El Estado: su abordaje desde una perspectiva teórica e histórica. En S. Lifszyc (Comp.) Introducción al conocimiento de la Sociedad y el Estado. Buenos Aires: Gran Aldea Editores.

Pascual, R. y Ghiotto, L. (2010). Reconceptualizando lo político: Estado, mercado mundial, globalización y neoliberalismo. Revista Argumentos, 23(64), 132-152.

Pellegrini, P. y Balatti, G. (2013). Arcas de Noé en el siglo XXI. Los bancos de semillas, entre la preservación y la apropiación de recursos naturales. VII Jornadas Santiago Wallace de Investigación en Antropología Social. Sección de Antropología Social. Instituto de Ciencias Antropológicas. Facultad de Filosofía y Letras, UBA, Buenos Aires.

Perelmuter, T. (2011). Bienes comunes vs. Mercancías: las semillas en disputa. Un análisis sobre el rol de la propiedad intelectual en los actuales procesos de cercamientos. Revista Sociedades Rurales, Producción y Medio Ambiente, (22), 53-86.

Perelmuter, T. (2017). Ley de semillas en Argentina: avatares de una reforma que (aún) no fue. Revista Interdisciplinaria de Estudios Agrarios, (47), 75-110.

Perelmuter, T. (2018). El agronegocio en la economía regional (pp. 33-45). En D. Beros y P. Kalmbach (Eds.) Riesgos y Desafíos del actual modelo de producción agrícola. Un abordaje interdisciplinario. Buenos Aires: Pastoral de Promoción del Cuidado de la Creación.

Pérez Miranda, R. (2002). Propiedad industrial y competencia en México. México: Ed. Porrúa. Pochettino, M.L.; Lema, V.; Hilgert, N. y Ladio, A. (2017). Los recursos genéticos en Argentina: caminos para su conocimiento, atajos para su acceso y avatares de su gestión. En Domesticación en el continente americano (vol. 2). Investigación para el manejo sustentable de recursos genéticos en el Nuevo Mundo. México: UAM.

Poth, C. (2013). Reconstruyendo la institucionalidad del modelo biotecnológico agrario: un enfoque sobre la Comisión Nacional de Biotecnología Agropecuaria (pp. 289-322). En C. Gras y V. Hernández (Coords.) El agro como negocio. Producción, sociedad y territorios en la globalización. Buenos Aires: Editorial Biblos.

Rapela, M. (2016). Ley 20.247 de Semillas y Creaciones Fitogenéticas: las razones para su actualización y los proyectos bajo análisis en Argentina. Revista Interdisciplinaria de Estudios Agrarios, (45), 69-97.

Teubal, M. y Palmisano, T. (2010). El conflicto agrario: características y proyecciones (pp.193-252). En N. Giarracca y M. Teubal (Coords.) Del paro agrario a las elecciones de 2009. Tramas, reflexiones y debates. Buenos Aires: Antropofagia. 
Teubal, M.; Domínguez, D. y Sabatino, P. (2005). Transformaciones agrarias en la Argentina. Agricultura industrial y sistema agroalimentario (pp.37-78). En N. Giarraca y M. Teubal (Coords.) El campo argentino en la encrucijada. Buenos Aires: Editorial Alianza.

Thwaites Rey, M. y Ouviña, H. (2018). El ciclo de impugnación al neoliberalismo en América Latina: auge y fractura (pp.17-61). En Estados en disputa: auge y fractura del ciclo de impugnación al neoliberalismo en América Latina. Ciudad Autónoma de Buenos Aires: El Colectivo.

Thwaites Rey, M. (2001). El Estado: notas sobre su(s) significado(s). Cuadernos de la Maestría en Hábitat y Vivienda. Universidad Nacional de Mar del Plata

Zorzoli, F. (2018). Capital, Estado y naturaleza: por una problematización económico-ecológico-política de la cuestión ambiental contemporánea. Estudios Socioterritoriales. Revista de Geografía, (24), 1-18.

\section{OTRAS FUENTES}

Acuerdo sobre Aspectos de los Derechos de Propiedad Intelectual que afectan al Comercio (ADPIC) de la OMC. Firmado el 15 de abril de 1994.

Convenio internacional para la protección de las obtenciones vegetales (UPOV). Revisado el 19 de marzo de 1991.

Convenio internacional para la protección de las obtenciones vegetales (UPOV). Revisado el 23 de octubre de 1978.

Decreto N².248/91: Desregulación económica, 1991.

Ley de Patentes de invención y Modelos de Utilidad, modificada por Ley No 24.572/96.

Ley de Semillas y Creaciones fitogenéticas $N^{a}$ 20.247, 1973.

Ley de Granos y Elevadores N 12.253, 1935.

Ley $N^{\circ} 27.118$ Reparación histórica de la agricultura familiar para la construcción de una nueva ruralidad en la Argentina

Reglamento de la Ley de Semillas y Creaciones fitogenéticas modificado por el Decreto No 2.183/91, 1991.

Resolución 125/08: Derechos de exportación. Fórmula de determinación aplicable a determinadas posiciones arancelarias correspondientes a cereales y oleaginosa, 2008.

Resolución 207/16: Se extraerán muestras del grano enviado a la $1^{\circ}$ entrega a fin de obtener información sobre la semilla que le dio origen a los fines del cumplimiento de la Ley $\mathrm{N}^{\circ}$ 20.247, 2016.

Resolución N²167/1196

\footnotetext{
Tamara Perelmuter es Doctora en Ciencias Sociales por la Universidad de Buenos Aires (UBA). Magister en Estudios Latinoamericanos por la Universidad Nacional de San Martín (UNSAM). Licenciada en Ciencia Política por la Universidad de Buenos Aires (UBA). Becaria Postdoctoral del Consejo Nacional de Investigaciones Científicas y Técnicas (CONICET). Investigadora del Instituto de Estudios sobre América Latina y el Caribe (IEALC). Coordinadora del Grupo de Estudios sobre Ecología Política desde América Latina (GEEPAL). Integrante del Grupo de Estudios Rurales y del Grupo de Estudios de los Movimientos Sociales de América Latina (GER-GEMSAL) del Instituto de Investigaciones Gino Germani. Principal trabajo de investigación: analizar el proceso de "cercamiento" de las semillas con hincapié en las transformaciones de la propiedad intelectual
} 
a partir de la inserción de la biotecnología al agro. El análisis lo realiza desde una mirada en donde conviven y se articulan diversos campos de investigación y acción: Ciencia Política; Geopolítica; Sociología Rural, Estudios de Ciencia y Tecnología; y sobre todo, Ecología Política y Marxismo Ecológico. Instituto de Estudios sobre América Latina y el Caribe IEALC. Facultad de Ciencias Sociales. Universidad de Buenos Aires. Marcelo T. de Alvear 2230, (1122) Ciudad Autónoma de Buenos Aires, Buenos Aires, Argentina, tamiperelmuter@gmail.com, ORCID https://orcid.org/0000-0003-4331-1872 